atmosphere in which convection occurs, of which there is ample observational evidence in these cases, the temperature will rise in the layers of increasing pressure in accordance with the known laws of adiabatic compression.

Sir James quotes the observed temperature of the visible cloud surface of Jupiter as - $138^{\circ} \mathrm{C}$. or $135^{\circ} \mathrm{K}$. Published estimates of the ammonia content of the atmosphere above this layer suggest a somewhat higher temperature, as the vapour pressure of ammonia falls to very low values about $145^{\circ} \mathrm{K}$.

Assuming the pressure at this level to be one terrestrial atmosphere (it is likely to be much lower) and that the ratio of the specific heats of the gases concerned is only $1 \cdot 33$, the temperature of the part of Jupiter's atmosphere which has a pressure of a million terrestrial atmospheres would be $13,000^{\circ} \mathrm{K}$., a temperature probably above the critical temperature of all substances. As a large part of Jupiter's atmosphere presumably consists of helium and the ratio of the specific heats of more complex gases rises quite rapidly with increasing pressure, the average value of this ratio is probably greater than 1.33 , in which case the high temperature quoted will be reached at a lower pressure.

The observations of the low temperature of Jupiter's visible surface show that there is no perceptible loss of heat by radiation from matter at high temperatures, so the whole of the mass of the planet within a layer, say, 6,000 miles below the visible surface must be at a temperature of tens of thousands of degrees absolute. If this conclusion is correct, it would make the explanation of the low average density of the larger planets much easier.

Royal Mint, london, E.C.3.

I HAD not meant to express any special views about critical temperature. It is true that the atmospheres of Jupiter and Saturn are above the critical temperatures of some substances, but I imagine critical temperatures become completely unimportant when the pressure is 10,000 or more times the critical pressure; the $a / v^{2}$ of Van der Waals becomes insignificant compared with the $p$, so that the equation of state reduces to $p(v-b)=\alpha \mathrm{T}$. Consequently I should expect all substances to behave similarly, whatever their ordinary critical temperatures may be, and in a way which will certainly be very different from that of the usual gas.

In this part of my lecture I was not expressing my own opinions, but describing the conclusions reached (admittedly rather speculatively) by Wildt and H. Jeffreys. These conclusions are based, among other things, on the extent to which Jupiter and Saturn are flattened by their rotation. As I explained in the spoken lecture, this tells us something as to the internal distribution of mass in these planets, although not enough, I think, to rule out Mr. Phelps's suggestion. It would be interesting to see this worked out in detail, although personally $I$ find it hard to reconcile the observational facts (persistence of red spot, etc.) with the possibility of Jupiter's atmosphere being convective down to a pressure of a million atmospheres.

Park House,

J. H. JEANS.

Wanstrow,

Somerset.

\section{The Rarer Constituents of South African Fireclays}

Some time ago I discussed the occurrence of vanadium and molybdenum in clays ${ }^{1}$. In their comprehensive and often neglected work on the refractory clays of Great Britain, Ennos and Scott ${ }^{2}$ reported the presence of various uncommon elements. Vanadium, barium, lithium, manganese, phosphorus, etc., are mentioned. Cobalt, nickel and chromium oxides were reported in traces. Apparently all the work was done chemically.

The following is a résumé of work on two clays and is typical of what is obtained on South African specimens.

\begin{tabular}{|c|c|c|c|}
\hline Element & $\begin{array}{c}\text { Lines examinec } \\
(\mathrm{A} .)\end{array}$ & $\begin{array}{c}\text { Fireclay from Middel- } \\
\text { burg, Transvaal }\end{array}$ & $\begin{array}{c}\text { Fireclay, } \\
\text { Boksburg }\end{array}$ \\
\cline { 1 - 3 } $\mathrm{V}$ & $3183 \cdot 42$ & Distinct & Distinct \\
$\mathrm{Be}$ & $\begin{array}{c}3189 \cdot 41 \\
2348 \cdot 62\end{array}$ & Distinct & Distinct \\
$\mathrm{Cu}$ & $3130 \cdot 56$ & \}Very faint & \}Very faint \\
& $3247 \cdot 55$ & Very faint & Nil \\
\hline
\end{tabular}

Care was taken that impurities in the carbon rods did not vitiate the results. A large automatic quartz spectrograph was used and a great deal of experimenting done to ensure that exposures and current strengths were adequate. In this work barium, tin, etc., were carefully looked for, but were not found. In fact, the ultimate chemical composition of these fireclays is very simple.

Manganese was tested for, both chemically and spectrochemically. Ennos and Scott reported manganese in British fireclays in amounts from a trace to 0.31 per cent MnO. Only in one case was this element noticed in a South African clay, and this was due to local deposition from downward percolating waters which had leached out the manganese oxides from the soils above. Mixed oxides of iron and manganese were deposited along the cracks and joints of the fireclays. However, away from the contaminated zones the same clays did not contain a trace of manganese. It was also noticed that the wet and dry tests for this element were very much more sensitive than spectrochemical ones.

Ennos and Scott reported the presence of chromium in Scottish clays in amounts up to 0.11 per cent $\mathrm{Cr}_{2} \mathrm{O}_{3}$. This element has so far not been detected in the clays of South Africa.

From the numerous analyses made it is evident that the detection of many of these elements requires special technique. For example, the heavy residues should be separated, and zirconium, barium, chromium, etc., looked for there. The extraction of vanadium and molybdenum after calcination has already been discussed. Spectro-chemical analysis in itself is not sufficient to report the absence of an element. It must be confirmed chemically.

Sulphur and phosphorus have always been found to be present in South African fireclays, by chemical means. Carefully made blanks are absolutely neces. sary in any work of this kind.

$$
\text { V. L. Bosazza. }
$$

University of the Witwatersrand, Johannesburg.

'Bosazza, V. L., Narura, 148, 746 (1940).

Ennos, F. R., and Scott, A., Spec. Rep. Min. Res. Gt. Brit., p. 84 (1924), 